Meta

Journal des traducteurs

Translators' Journal

\title{
Logodiversity and Translation
}

\section{Francis Henrik Aubert}

Volume 41, numéro 2, juin 1996

Traduction et terminologie au Brésil

Translation and Terminology in Brazil

URI : https://id.erudit.org/iderudit/001918ar

DOI : https://doi.org/10.7202/001918ar

Aller au sommaire du numéro

Éditeur(s)

Les Presses de l'Université de Montréal

ISSN

0026-0452 (imprimé)

1492-1421 (numérique)

Découvrir la revue

\section{Citer cet article}

Aubert, F. H. (1996). Logodiversity and Translation. Meta, 41(2), 192-195.

https://doi.org/10.7202/001918ar

\section{Résumé de l'article}

L'auteur définit la logodiversité comme l'affinité entre la biodiversité, la linguistique et la diversité culturelle et il s'interroge sur le rôle de la traduction en tant qu'instrument pour la préservation de la logodiversité ou comme facteur contribuant au grand silence de la polyphonie humaine. d'utilisation que vous pouvez consulter en ligne.

https://apropos.erudit.org/fr/usagers/politique-dutilisation/ 


\title{
LOGODIVERSITY AND TRANSLATION
}

\author{
FRANCIS HENRIK AUBERT \\ Universidade de São Paulo, São Paulo, Brazil
}

\begin{abstract}
Résumé
L'auteur définit la logodiversité comme l'affinité entre la biodiversité, la linguistique et la diversité culturelle et il s'interroge sur le rôle de la traduction en tant qu'instrument pour la préservation de la logodiversité ou comme facteur contribuant au grand silence de la polyphonie humaine.
\end{abstract}

\section{Abstract}

The author defines logodiversity as an affinity between biodiversity and linguistic and cultural diversity. He looks at translation as both an instrument for the preservation of logodiversity and as a contributing factor to the silencing of human polyphony.

The headlines and controversies focusing on the issue of the preservation of biodiversity, which we have recently been witness to during the RIO-92 World Conference, are a clear indication that this matter is of essence to our common future.

The many theories, investigations and approaches which have focused on biological diversity deal mainly with the botanical, zoological, physical and chemical aspects of this our sub-lunar world, as well as with the many interactions and interdisciplinary fields (climatology, oceanography, agriculture, industrial conservation and recycling, to mention but a few). Falling under the Environmental Sciences, these areas of scientific, political and social thought see mankind simultaneously as agent and patient of processes affecting the chances of survival of homo sapiens as a living species of the planet Earth.

But mankind's environment extends beyond the physical, chemical and biological realities, to encompass the many cultures of Humanity and the many languages in which these different cultures find expression. If, on one hand, we are heirs to a multifaceted biological heritage which everybody agrees requires the combined efforts - and, one must admit, the full acceptance of sacrifice - of the many human communities in order to ensure its preservation (we may not always agree on the most efficient ways and means to attain such a goal), we also possess, on the other hand, an equally multifaceted cultural and linguistic heritage, of great complexity and variation and which, to a very large extent, can also be perceived as being at risk.

Indeed, much as the dodo bird and the panda, languages and cultures have died out or have been perilously pushed to the last brink of existence, under the domination of other cultures and other languages wielding greater political, economic and demographic clout. And, most probably, just as we have the best of reasons for grieving the disappearance of the Tasmanian wolf, our loss is great indeed over the final silencing of each dialect and each language, from the Dalmatian to the Tupinambá. This affinity between biodiversity and linguistic and cultural diversity (herein referred to as logodiversity or, alternatively as polyphony) is evidenced by the concerns expressed in several debates which occurred during the Rio-92 World Conference.' As Rónai (1970) put it well before the environmental concern became generalized, “... Were mankind to see things through a single prism, it would more easily accept the mould of the unitary thought, of massification. On consideration, the multiplicity of languages can still be seen as one of the strongholds of freedom." 
This paper will examine the role of translation as an instrument for the preservation of logodiversity and/or as a factor contributing to the gradual silencing of human polyphony.

Let it be stated from the outset that all cultural exchanges and contacts create the need for translation. Except in cases of extermination by war, pestilence or famine, interaction between different cultures, even within a dominant/dominated relationships, does not attain the final stage of assimilation of the weaker by the stronger party without prior translational activity, be it oral and/or written. Therefore, it seems reasonable to assert that translation is an inevitable component of any such interaction, and that its potential should be examined in some detail in order to ascertain its role in the preservation/destruction of logodiversity.

Whatever the specific circumstances of a given translational act, the moment of translation is a different moment, more or less distant in space and in time from that in which the first message (the "original" text) was produced. This holds true even if such distance can be measured in seconds (as in the case of conference interpretation) and/or if the subjective space is the same (i.e., when the author translates/interprets him/herself). The purpose is no longer the same, the codes and referents are different, the channel may be different, and the receivers may or may not be the same or, if they are, they might be placed differently in space and in time. Presuppositions and motivations may differ somewhat from those prevalent during the production of the original message.

These comments are not intended as a criticism of translation as such - in a sense they point out its supposed limitations - nor do they lend credence to the recurrent but misguided catch phrase tradutori, tradittori. On the contrary, these differing conditions explain the very existence of translation, the primary source of the translational impulse; translation only comes into its own in an efficient manner inasmuch as it incorporates such differences. But, as is fairly evident, the inevitability, this intrinsic of such differentiation carries with it a certain risk: that of silencing the original voice, in favour of another, the former being totally consumed by the latter. Without pursuing the metaphor much further, this might be described as a feast of cultural and linguistic cannibalism.

In fact, the original speech act is an act of inter-subjective interaction and, as such, is performed under certain social conditions which must be observed by all participants, if communication is to take place. The subsequent translational act is nothing but a new speech act, in a new context of inter-subjective interaction, and, as such, is required to take social constraints into account. These constraints may at times be similar; in fact, they very often are, but are never strictly identical to those prevailing in the original speech act. Any priority ascribed to the recipient of the translation is thus not merely one of several options: a target-centered translation strategy as opposed to a source-centered translation strategy, but also something which is essential to translation as a whole, under any circumstances. And, by focusing on the intended audience of the translation, as is required in any communicatively efficient translation act, the translator will of necessity have to model and remodel the message - most certainly not only at its most elementary denotative level - so as to ensure its intelligibility, a single step away from its full assimilation.

Texts and conditions which facilitate this short step, to the general satisfaction of all parties concerned, are countless. Indeed, they are taken in the vast majority of everyday translation throughout the world. Unlike other features of translation previously discussed, this last step is not inevitable, but should be perceived as an option. As such, it admits its contrary. In other words, it is a deliberate attempt by the translator to reinstate the original or source-text (even if we are to admit that what is reinstated is actually the translator's understanding of what we may call the original text). From a strictly technical 
view point, this is achieved in one of two ways. By tapping into the potential inherent in the prevailing linguistic and cultural systems, or by deliberately introducing outside elements, new words, new modes of expression, new cultural values, new Weltanschauungen are generated. In either case these new forms are imitative - in the Classical sense of the term - and are not alien to the text world of the source text.

This approach, which we prefer to call the "source-centered approach," 2 may result in a rich but somewhat "heavy" product, difficult to assimilate, with a disturbing effect on the cannibalistic feast we just referred to. New rhythms, new voices, foreign to the recipients of the translation, will manifest themselves, and the linguistic and cultural perception of the target readers/listeners will never be quite the same after their arrival on the scene. Here, the risk is not that of silencing or of prudish dismissal but one of dissonance, which may, in turn, generate anything from the joy and satisfaction of discovering new outlooks or long-sought exoticism, to experiencing mixed feelings of surprise at the perception of "oddities" or outright rejection and disruption of the communicative flow. At times, selfsufficiency will give rise to tinges of xenophobia resulting from the recipient community's lack of self-assurance in terms of its own linguistic and cultural identity.

Despite all these risks, however, the source-centered approach seems to better contribute towards sustaining logodiversity and polyphony. By using the tools of translation in this manner, despite the inevitable filtering of the interpretation(s) and the limitations imposed by the intelligibility requirements at reception, it is possible to provide some space for the original voice. This option enables other realities to be perceived - albeit partially -, not only in terms of their factual and individual existence but in terms of their meaningful consistency within the framework of cultural otherness. It is this perception of otherness and of the meaningful consistency which fees each member of the target community from the shackles of linguistic and cultural conditioning, from the bondage of a limited perspective on reality. In this sense, as Rónai points out, translation may well be an efficient instrument of individual and collective freedom.

The relationship between languages and cultures is not necessarily a balanced tugof-war between peers. The dominant/dominated relationship we referred to earlier in this paper is also apparent - as one might well expect, in the translational context. Depending on whether the direction of the translational act is established from a dominant language-culture to a dominated language-culture, from a dominated languageculture to a dominant language-culture, or between two dominant or two dominated language-cultures, the effects of the approach - source-centered or target-centered - on the preservation of logodiversity will differ somewhat.

Thus, although the source-centered approach appears to be the most convenient form of translation in terms of preserving and, indeed, spreading logodiversity within the context dominated $\rightarrow$ dominant (e.g. translation from indigenous languages to the colonizers' languages), in translation between two dominant languages (e.g. French/German within the current European framework) or from/to any two languages and cultures between which no imbalance of cultural and/or linguistic status is evident (e.g. Norwegian/Portuguese), the consequences of this approach are not the same in each situation. In the first case, the source-centered approach sustains the voice of the dominated before the dominant speech; in the second, it gives its modicum of contribution to the maintenance of the balance of power; in the third, it ensures mutual enrichment without incurring the side-effect of silencing one of the parties.

In the dominant $\rightarrow$ dominated relationship, however, the situation appears to be much more intricate. Within this framework, the source-centered option may, depending on the specific reception circumstances, intensify the domination process, precisely by the introduction and ingraining of forms and values of the source language-culture in the 
target language-culture. On the other hand, the clear presence of the traces of such forms and values will contribute towards enhancing the otherness, the non-universality, which, if clearly perceived by the recipient community, will, conversely contribute to the maintaining of the respective cultural identities.

On the converse, by resorting to the cultural cannibalism of the target-centered option, one might be setting up a socioculturally efficient - yet, textually speaking, rather ruthless - device for the defense of the context in which the translation is received. Here, however, sufficient scope is allowed for the manipulation of cultural values, generating an illusion of universality. In fact, the values and forms of the first text may be upheld fairly untouched. In other words, the target-centered option which, at first sight, appears to provide for a better assimilation of the first text into the forms and values prevailing in the target language-culture, may actually represent a masking of the otherness, so as to render it acceptable as an integral part of the target language-culture, or, alternatively, generate an illusion of universality, the results of which are less perceptible but which tend to dilute the diversity which is claimed here to be worthy of defense and preservation.

Translation, not unlike all other human activities, is essentially dynamic, synchronically variable and diachronically undergoing constant change. In the particular case of the Luso-Brazilian and Spanish American languages and cultures, these features will vary according to the language-culture they are paired with, sometimes as dominant, other times as dominated, at other times even neutral in the struggle for cultural power. Several dominance patterns may come simultaneously into play in complex interactions. For instance, during the literary renewal which Spanish America experienced at the turn of the 20 th century, the dominant matrix was Spanish Literature and it was by resorting to translations from other literatures and cultures, also dominant (basically from the French and the Anglo-American heritages), that the literary autonomy of the Spanish-speaking New World came about (Aparicio 1991). As a necessary and unavoidable tool of cultural and linguistic policy, translation may, thus, operate both in favour of the preservation and expansion of logodiversity as well as, in the opposite sense, contribute to uniformity. Translation is bivalent, not neutral. To a large extent, it is incumbent on the translator, as an individual, as the subjective medium for cultural interaction to take full responsibility for the options to be chosen and their consequences be they or constructive or destructive.

Notes

1. E.g. the round-tables "Mudanças Globais versus Diversidade Sociocultural" [Global Changes versus Sociocultural Diversity] and "Diversidade Biologica" [Biological Diversity], Scientific Programme of the National Workshop, Rio de Janeiro, 1 a 3 de junho, 1992. Apud Jornal da USP, year VI, no. 219, June $8 / 14,1992$.

2. The terms "semantic" and "communicative" translation proposed by Newmark (1981) to refer to two fundamental options, seem rather infelicitous, given that all and any translations, whatever the approach chosen, are intended to communicate, and do so based on the many possible levels of semantic equivalence.

\section{REFERENCES}

APARICIO, F. R. (1991): Instancias de la Traducción Literaria en Hispanoamérica en el Siglo Veinte, Gaithersburg, Hispamérica.

NEWMARK, P. (1981): Approaches to Translation, Oxford, Pergamon.

RÓNAI, P. (1970): Babel \& Antibabel, São Paulo, Perspectiva. 